\title{
Smoke, fire and mirrors: The e-cigarette debate
}

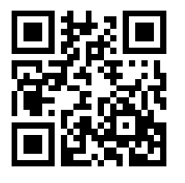

Can a rechargeable battery, linked to an atomiser and cartridge of liquid nicotine, 'massively' reduce the individual and population risks of traditional cigarette smoking? Or is the increasingly ubiquitous e-cigarette a dubious, poorly-controlled 'aid to quitting', resulting in actual dual use with unacceptably high toxin levels? The jury is out scientifically, with South African role players on either side producing evidence for and against the device.

Global sales of e-cigarettes are projected to reach R17 billion by year end, which Wells Fargo Securities estimates to be a $240 \%$ increase over last year. However,
Yussuf Saloojee, the executive director of South Africa's National Council Against Smoking, said the devices don't deliver enough nicotine in a palatable way to satisfy smokers (they deliver a third of ordinary cigarettes' nicotine load), thus ruling them out as cigarette replacements. He predicts that addicts will use them in non-smoking areas, but light up 'properly' again where they legally can, thereby actually increasing their nicotine load. Although 'higherend' e-cigarette brands are less toxic than ordinary cigarettes, he said the combination of multiple manufacturers and the absence of a regulatory authority controlling the purity of the products, meant poisons like chromium, acrolein and formaldehyde will be found to varying extents in various products. He also believes our struggling Medicines Control Council, which lists e-cigarettes as a Schedule 3 drug, will be wholly unable to control distribution.

Saloojee was arguing against influential harm-reductionists Derek Yach, South African-born Executive Director of the Vitality Institute, and Canadian epidemiologist David Sweanor. It was Yach and Sweanor who, 20 years ago, first briefed the ANC on tobacco taxation as an effective control strategy, arguably launching South Africa's increasingly progressive anti-tobacco policies. The pair calculate that South Africa's tobacco policies - particularly high tobacco taxation - have redirected R120 million back 


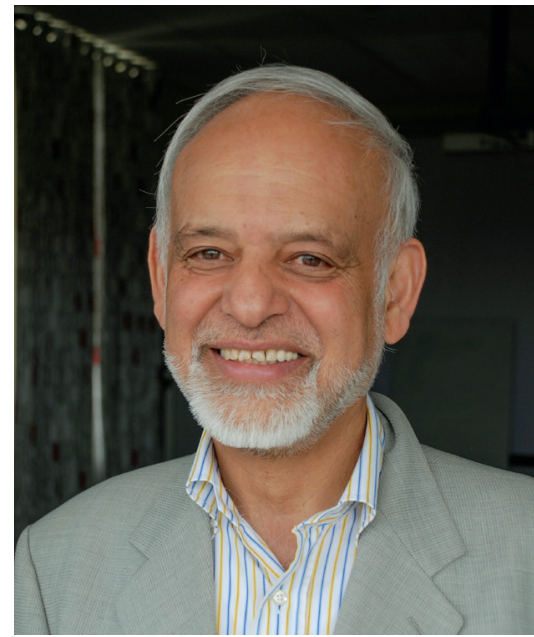

Yussuf Saloojee, Executive Director of South Africa's National Council Against Smoking.

into the economy and saved 1.5 million lives over the last two decades.

\section{Past tobacco reduction measures 'a Trojan horse'}

Saloojee says the idea of modifying the tobacco product to make it less harmful is hardly new. From 1966 through to the 1980s, the US and UK governments erroneously promoted low-tar/low-nicotine cigarettes, with the UK even including tables to guide smokers in selecting brands. However, a 2006 United States District Court ruling found cigarette manufacturers guilty of multiple counts of deception and fraud in promoting health benefits for cigarettes labelled 'low-tar', 'light', 'ultra-light', 'mild' and 'natural' over more conventional brands.

Saloojee warned that tobacco corporates' overall goal is to dissuade smokers from quitting, and that e-cigarettes are merely another means to this end. He conceded, however, that cigarette smoke is the worst killer, delivering a cocktail of over 4500 chemicals along with the nicotine, and that developing less toxic alternatives for the long-term delivery of nicotine can potentially reduce the harms that flow from nicotine addiction.

\section{Saloojee said the tobacco corporates' overall goal is to dissuade smokers from quitting, and that e-cigarettes are merely another means to this end.}

He says that while it is boasted that the e-cigarette can provide 'nicotine, sans tars and toxins', the claims that eliminating smoke removes nearly all the danger and that e-cigarettes slake nicotine cravings are false. He cited a study by Bullen et al., ${ }^{[1]}$ which compared nicotine absorption after using an e-cigarette, a Nicorette nicotine inhalator and a conventional cigarette. On average, the e-cigarette increased serum nicotine to a peak of $1.3 \mathrm{ng} / \mathrm{ml}$ in 19.6 minutes, the inhalator to $2.1 \mathrm{ng} / \mathrm{ml}$ in 32 minutes and cigarettes to $13.4 \mathrm{ng} / \mathrm{ml}$ in 14.3 minutes.

\section{'More harm than good' - Saloojee}

Explained Saloojee: 'The test e-cigarette did not deliver as much nicotine as a regular cigarette, nor as fast.' For him, this failure to mimic a cigarette is a major shortcoming. 'If people cannot get the nicotine fix they need to allay withdrawal symptoms and satisfy cravings, they will not switch to exclusive use of the product.' He believes the current patterns of e-cigarette use are probably consistent with the device's limited ability to deliver nicotine, meaning it is being used as a smoking cessation aid or to supplement regular cigarettes.

He said that as long as people continue to smoke even a few cigarettes a day, the risk of dying early remains excessive; compared with never smoking, smoking 1 - 4 cigarettes a day carries a $60 \%$ excess risk of dying early and 5 - 9 a day doubles the risk of dying early. According to Saloojee, the e-cigarette's failure to compete with conventional cigarettes in delivering nicotine is 'to be expected', given how crude it is in comparison with the highly-engineered modern cigarette (which offers optimal nicotine delivery in a palatable way via the inclusion of ammonia and sugar) He said there is no conceivable reason why e-cigarette manufacturers would be any less averse to breaking the law than conventional cigarette companies, as evidenced by their promoting sales by ordinary retailers instead of only by prescription from a pharmacist, as required for a Schedule 3 drug.

Saloojee concluded that if for every person who used e-cigarettes that comply with the highest regulatory standards, there was one fewer person smoking conventional cigarettes, 'that would be good. However, there is no evidence that this will happen in the foreseeable future, as e-cigarettes simply cannot compete as nicotine delivery devices. 'Asking heavy smokers to switch to exclusive use of e-cigarettes is like asking heavy drinkers to switch to non-alcoholic or low-alcohol beer.'

\section{SA on the right track}

Saloojee advised Yach and like-minded e-cigarette advocates to help South Africa complete its unfinished traditional tobacco control policies, instead of 'looking for the next breakthrough in tobacco control. He proposed that the immediate focus should be on making public places 100\% smoke-free, on plain packaging, and on revising tobacco excise tax policies to make tobacco products progressively less affordable over time.

Yach and Sweanor cited Sweden's experience with 'snus' (flavoured chewable tobacco) as proof-of-concept that disease risk can massively be reduced by using a different delivery system. They say that failing to address the nicotine delivery vehicle is equivalent to trying to reduce traffic fatalities while ignoring the modifiable risks in automobiles themselves. They see it as 'extraordinary', that tobacco control activities have centred on where cigarettes may be sold, their price, where they can be used, what warnings may be displayed and the disclosure of toxic constituents.

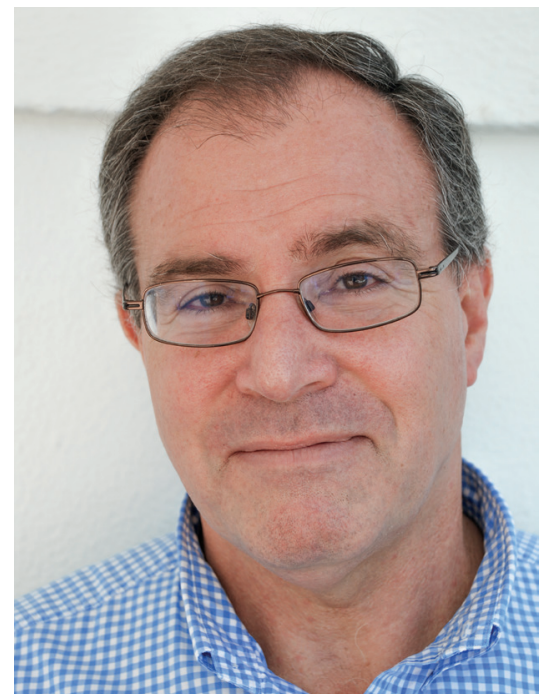

Dr Derek Yach, Executive Director of the Vitality Institute.

In an article in this issue of the $S A M J$, Sweanor and Yach point out: 'We have known for decades that "smokers smoke for the nicotine, but die from the smoke", a point now reiterated ... by the Royal College of Physicians and others who call for harm reduction principles to be applied.'[2]

\section{Chris Bateman}

chrisb@hmpg.co.za 1. Bullen C, McRobbie H, Thornley S, et al. Effect of an electronic
nicotine delivery device (e cigarette) on desire to smoke and
withdrawal, user preferences and nicotine delivery: Randomised
cross-over trial. Tob Control 2010;19:98-103. [http://dx.doi.
org/10.1136/tc.2009.031567]
2. Sweanor D, Yach D. Looking for the next breakthrough in
tobacco control and health. S Afr Med J 2013;103(11):810-811. [http://dx.doi.org/10.7196/SAMJ.7513]

S Afr Med J 2013;103(11):818-819.

DOI:10.7196/SAMJ.7563 